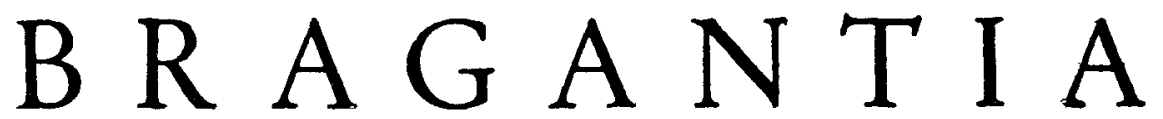

Boletim Cientifiço do Instituto Agronômico do Estado de São Paulo

Vol. 27

Campinas, março de 1968

N. ${ }^{\circ} 9$

\title{
COMPORTAMENTO DE VARIEDADES DE SOJA CUJAS SEMENTES FORAM INOCULADAS COM DIFERENTES MISTURAS DE ESTIRPES DE RHIZOBIUM, EM LATOSOL ROXO DO ESTADO DE SÃO PAULO ( $\left.{ }^{1}\right)$
}

H. A. A. Mascarenfas e Shiro Miyasaka, engenheiros-agrônomos, Seģão de Leguminosas, Instituto Agronômico, Dr. D. WeBer, microbiologista, Instituto de Pesquisas I.R.I., E. S. Freire, engenheiro-agrônomo (2), GuIdo di 'Sord, engenheiro-agrônomo, Listação Experimental de Ribeirão Prêto, Rúter Hiroce, engenheiro-agrônomo, Laboratório de Análise lioliar, Instituto Agronômico, e J. S. Tango, engenheiro-agrônomo, Centro Tropical de Pesquisas e Tecnologia de Alimentos

\section{SINOPSE}

Fm solo Latosol Roxo, estudon-se o comportamento de cinco variedades de soja cujas sementes foram inoculadas, ou não, com diferentes misturas de estirpes de Rhizobium. Na produção de sementes, a variedade Hardee foi equivalente à IAC-1 c superior às variedades $\mathrm{I}-2006, \mathrm{~L}-571 \mathrm{e}$ Bienville. $1 \mathrm{AC}-1$ também foi superior a Bienville. A adubação nitrogenada não aumenton a produção, e as pequenas respostas aos inoculantes não foram significativas. Conquanto a área experimental nunca tivesse cultura de soja, a nodulação foi intensa cm todos os canteiros, e não se notou aumento em conseqüência da inoculação experimental.

\section{1 - INTRODUÇÃO}

No Ensaio Nacional de Variedades de Soja, programado pelo $\mathrm{Mi}$. nistério da Agricultura, no qual as variedades em estudo foram inoculadas com um ínico inoculante comercial, observaram-se, em 1964-65, diferenças altamente significativas entre as variedades, com relação à nodulação $\left({ }^{3}\right)$. Daí suporem os coordenadores do Ensaio que exista especificidade entre variedades e inoculantes.

Para investigar o assunto e determinar o inoculante mais adequado

(1) Recebido para publicação em 2.3 de outubro de 1967.

(2) Contratado pelo Conselho Nacional de Pesquisas, para colaborar com técnicos do Instituto Agronomico. Sua colaboraçăo no presente trahallio foi prestada na apresentação e interiretaçăo dos resultados obtidos.

(3) Comunicaç̃o verbal dos Eng. ${ }^{\circ}$ Agr.os Johanna Döbereiner, do Serviço Nacional le Pesquisas Agronomicas, Ministério da Agricultura, e R. J. Jardim Freire, da Secretaria da Agricultura do Estado do Rio Grande do Sul. Os autores agradecem a êsses técnicos o fornecimento do plano experimental e dos inoculantes necessários à sua execução. 
às variedádes que se mostrassem mais produtivas, foi organizado um plano, de cuja execução participariam várias instituições científicas, segundo o qual diversas variedades de soja (Glycine max (L.) Merril) seriam inoculadas com quatro misturas de estirpes de Rhizobium.

O objetivo do presente trabalho é apresentar os resultados de uma experiência que o Instituto Agronomico, como participante do citado programa experimental, realizou em 1965-66.

\section{2 - MATERIAIS E METODOS}

O esquema experimental constou de parcelas subdivididas, distri. buidas em blocos ao acaso, com três repetições. J)as seis parcelas de cada repetição, quatro foram adubatas com PK e receberam sementes inoculadas com diferentes misturas de estirpes de Rhizobium; das outras duas, plantadas com sementes não inoculadas, uma foi aduharla com l'K e a outra com NlK.

Os inoculantes comparados foram os seguintes:

A - Mistura de dez estirpes de Rhizobiam da Secretaria da $\Lambda$ gricultura do Estado do Rio Grande do Sul.

$B$ - Mistura de dez outras estirpes de $R$. da Secretaria da Agricultura do Rio Grande do Sul.

$C$ - Mistura de der estirpes de $R$. dos Estados Unidos da América do Norte.

$D$ - Mistura de dez estirpes de $R$. do Instituto de Pesquisas e Experimentação Agropecuárias do Centro-Sul, do Ministério da Agricultura.

As cinco subparcelas de cada parcela foram ocupadas pelas variedades L-571, L-2006, IAC-1, selecionadas pelo Instituto Agronômico; Hardee e Bienville, de sementes fornecidas pelo Instituto de Pesquisas I.R.I. Da experiência constou mais uma variedade, que foi excluída na ocasião da colheita, por não apresentar. as características próprias.

Da adubação usada, como fontes de nitrogênio, fósforo e potássio empregaram-se, respectivamente, $30 \mathrm{~kg} /$ ha de $\mathrm{N}$, como sulfato de amônio; $100 \mathrm{~kg} / \mathrm{ha}$ de $\mathrm{P}_{2} \mathrm{O}_{5}$, como superfosfato simples; $40 \mathrm{~kg} / \mathrm{ha}$ de $\mathrm{K}_{2} \mathrm{O}$, como cloreto de potássio. O fósforo e o potássio foram empregados na ocasião do plantio, em sulcos situados a $5 \mathrm{~cm}$ ao lado dos destina- 
dos às sementes; o nitrogênio, em cobertura, vinte dias após a germinação.

A área experimental recebeu, 1,5 mês antes do plantio da soja, $3 \mathrm{t} / \mathrm{ha}$ de calcário com $38 \%$ de $\mathrm{CaO}$ e $9 \%$ de $\mathrm{MgO}$. Metade dessa dose foi espalhada antes da aração; a outra metade, depois da aração, mas antes da gradagem.

A inoculação das sementes foi efetuada na véspera do plantio, pelo processo habitual, tendo-se o cuidado de evitar a contaminação dos lotes de sementes com estirpes que não lhes eram destinadas.

As subparcelas constaram de quatro fileiras de $6 \mathrm{~m}$, com o espaçamento de $70 \mathrm{~cm}$; contudo, para a colheita só foram aproveitadas as duas fileiras centrais, das quais se excluiram $50 \mathrm{~cm}$ nas cabeceiras, de sorte que a área útil ficou reduzida a $7 \mathrm{~m}^{2}$. Por metro linear de fileira empregaram-se 25 sementes. Não se fêz desbaste.

Instalou-se a experiência na listação lixperimental de Ribeirão Prêto, numa glebar de latosol Roxo, segundo a classificação da co. missão de Solos do Ministério da $\Lambda$ gricultura (2). A área escolhida, que nunca teve cultura de soja, havia sido cultivada várias vêzes com algodão adubado com NPK, e em seguida, duats vêzes com milho sem ardubo. No ano anterior an da experiencia ficon em pousio. Análises

QUADRo 1. - Características físicas e químicas (1) do solo (Latosol Roxo) utilizado para a competição de variedades de soja e inoculantes realizada em Ribeirão Prêto

\begin{tabular}{|c|c|c|c|}
\hline Característica & Valor & Característica & Valor \\
\hline ANÁLISE FÍSICA & & & \\
\hline Areia grossa $-\% \ldots$ & 10,0 & $\mathrm{~N}-\% \ldots \ldots \ldots$ & 0,15 \\
\hline Areia fina $-\% \quad \ldots \ldots \ldots$ & 26,8 & $\mathrm{PO}_{4}{ }^{-3}-$ e.mg ${ }^{(2)}$ & 0,06 \\
\hline Limo $-\%$.......... & 27,0 & $\mathrm{~K}+{ }^{2}-\mathrm{e} . \mathrm{mg}\left({ }^{3}\right) \ldots \ldots$ & 0,08 \\
\hline Argila $-\% \ldots \ldots \ldots$ & 36,2 & $\mathrm{Ca}^{2}{ }^{2}-\mathrm{e} . \mathrm{mg}\left({ }^{3}\right) \ldots$. & 2,25 \\
\hline ANÁLISE QUÍMICA & & $\mathrm{Mg}^{+2}$ - e.mg ( $\left.{ }^{3}\right) \ldots$ & 0,80 \\
\hline $\mathrm{pH} \quad \ldots \ldots \ldots$ & 5,50 & $\mathrm{~A} 1+3-\mathrm{e} \cdot \mathrm{mg}\left({ }^{3}\right) \ldots \ldots \ldots$ & $\operatorname{tr}$ \\
\hline $\mathrm{C}-\% \ldots \ldots \ldots \ldots$ & 1,83 & $\mathrm{H}++\mathrm{Al}^{+3}-\mathrm{e} \cdot \mathrm{mg}\left(^{3}\right) \ldots$ & 4,30 \\
\hline
\end{tabular}

(1) Análises efetuadas na Seção de Agrogeologia, com a colaboração do Eng.o-Agr.o Rernardo van Raij.

(2) Solúvel em $\mathrm{H}_{2} \mathrm{SO}_{4} 0,05 \mathrm{~N}$, em $100 \mathrm{~g}$ de T.F.S.A.

(3) Trocáveis, em $100 \mathrm{~g}$ de T.F.S.A. 
física e química de uma amostra composta do solo utilizado, tirada antes da calagem, são apresentadas no quadro 1 .

O plantio da soja, durante o qual se observaram os cuidados necessários para evitar contaminação das sementes diferentemente inoculadas, foi efetuado no dia 17 de novembro de 1965; a colheita, a 12 de abril de 1966.

As datas do início do florescimento (quando abriram as dez primeiras flores) foram anotadas separadamente para cada variedade.

Aos quarenta dias após a germinação, extrairam-se cuidadosamente, ao acaso, dsz plantas das bordaduras de cada subparcela. Depois de lavar as raízes e as bases dos caules, as plantas foram postas a secar (ao ar) e pesadas. Dêsse material, retiraram-se as fôlhas para análise, bem como os nódulos, que foram contados e pesados.

Os teores de óleo e proteina das sementes colhidas foram determinados em amostras compostas das produções das três repetições de cada tratamento.

\section{3 - RESUITADOS}

O tempo correu favoràvelmente durante o ciclo da soja. A germinação se processou em oito dias, e os «stands» iniciais, verificados em 30 de novembro, foram muito bons, exceto o da variedade Bienville, que se mostrou inferior aos das demais. Contudo, as plantas dessa variedade sobreviveram em maior proporção, de sorte que os «stands» finais foram todos satisfatórios e suficientemente uniformes.

Florescimento - As plantas começaram a florescer entre 26 de dezembro de 1965 e 11 de janeiro de 1966. Houve apreciáveis diferenças entre as variedades. Enquanto L-571 e IAC-1 se mostraram mais tardias, pois iniciaram o florescimento 47 dias após a germinação, Bienville, a mais precoce, apresentou as primeiras flores aos 31 dias de idade. Hardee e I.-2006, com 38 e 40 dias, colocaram-se em posição intermediária.

Pêso das plantas e nodulação - No quadro 2 encontram-se os resultados da amostragem efetuada quarenta dias depois da germinação. Vê-se que, nessa ocasião, o pêso médio das plantas adubadas com NPK (sem inoculantes) foi um pouco superior ao das demais, e que 
Hardee apresentou, em média dos tratamentos, plantas mais pesadas que as das outras variedades.

A nodulação (quadro 2) foi muito boa em todos os tratamentos, principalmente no que só recebeu PK (sem inoculantes). Em média das variedades, ela foi menor no tratamento adubado com NPK e nos que receberam $\mathrm{PK}+$ inoculantes. No que se refere ao pêso dos nódulos, a depressão provocada pela adubação nitrogenada atingiu tôdas as variedades, e a causada pelos inoculantes só deixou de se manifestar quando se usou a mistura $B$ na variedade L-2006. Aliás, neste caso, a influência favorável da inoculação foi desprezível.

Em média dos tratamentos com e sem inoculantes, Hardee apresentou maior nodulação que as outras variedades. Destas, as menos favorecidas foram IAC-1 e Bienville.

$\mathrm{Na}$ presente amostragem, a correlação entre o pêso das plantas e o dos nódulos não foi significativa $(r=0,19)$. Todavia, a existente entre o número e o pêso dos nódulos foi positiva e altamente significativa $(r=0,81)$.

Análise foliar - A análise das fôlhas foi efetuada no material colhido quando as plantas tinham quarenta dias de idade. Segundo o teste de Tukey ao nivel de $5 \%$ o teor de nitrogênio na matéria sêca, que atingiu $3,13 \%$ no tratamento NPK, foi significativamente superior ao do tratamento $\mathrm{PK}+$ inoculante $C(2,78 \%)$, mas não diferiu estatisticamente dos observados nos demais tratamentos.

Quanto às variedades, os mais altos teores de nitrogênio, de 3,15 , 3,00 e 2,96 por cento, estatisticamente equivalentes, foram encontrados nas fôlhas de Hardee, L-571 e Bienville, respectivamente; os mais baixos, de 2,86 e 2,69 por cento, também equivalentes, nas de L-2006 e IAC-1. O desta última variedade foi estatisticamente inferior aos de Hardee, L-571 e Bienville, ao passo que o de L-2006 se mostrou equivalente ao de Bienville.

Convém lembrar que, embora as variedades florescessem em datas diferentes, por vêzes muito diferentes, a amostragem para a análise foliar foi realizada numa data única, o que talvez tenha prejudicado a comparação do parágrafo anterior.

Produção de sementes - Não obstante as divergências observadas no início do florescimento, as variedades estudadas atingiram 0 ponto de colheita aproximadamente na mesma data, 138 dias depois da germinação (146 dias depois do plantin) . 


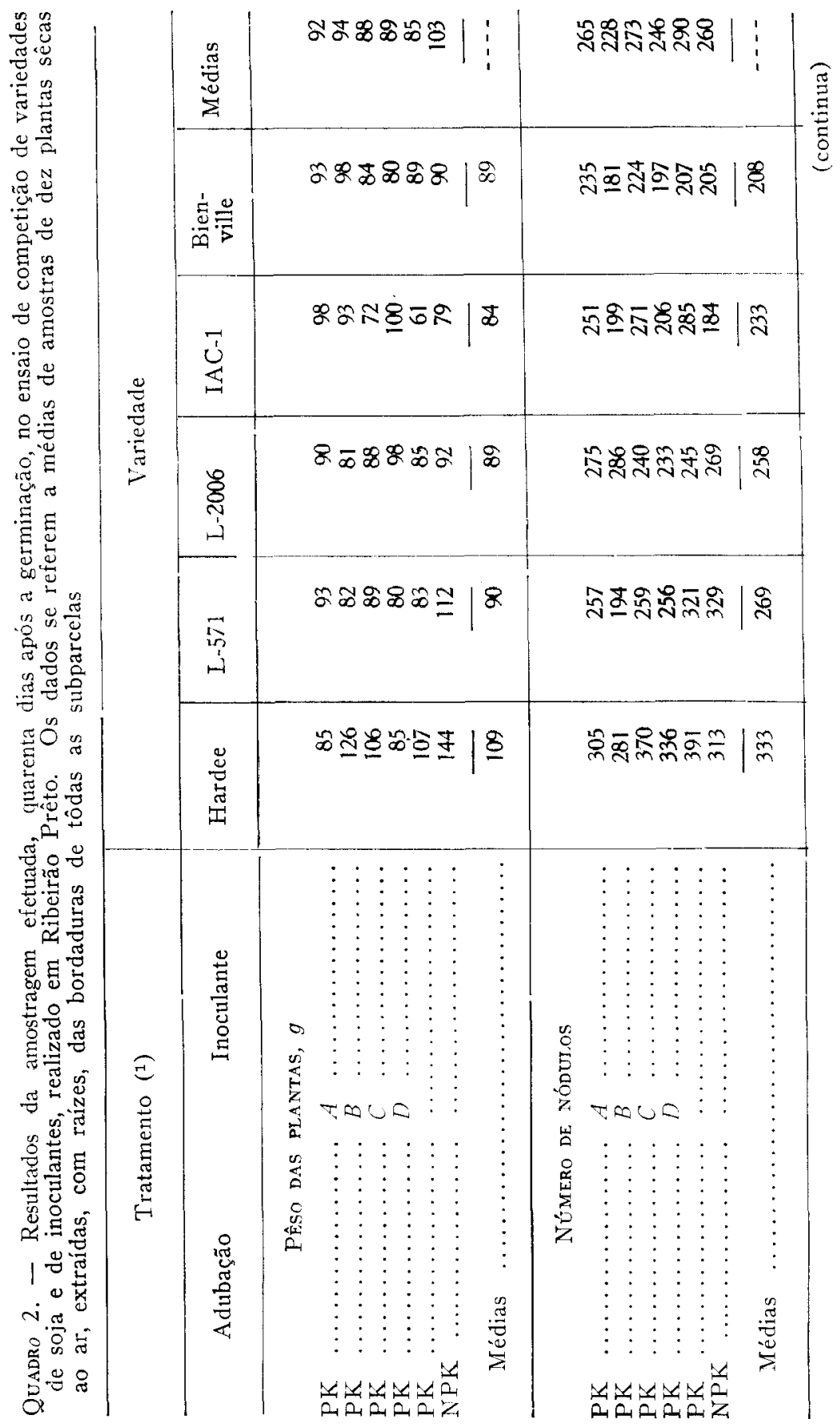


H. A. A. Mascarenhas \& outros

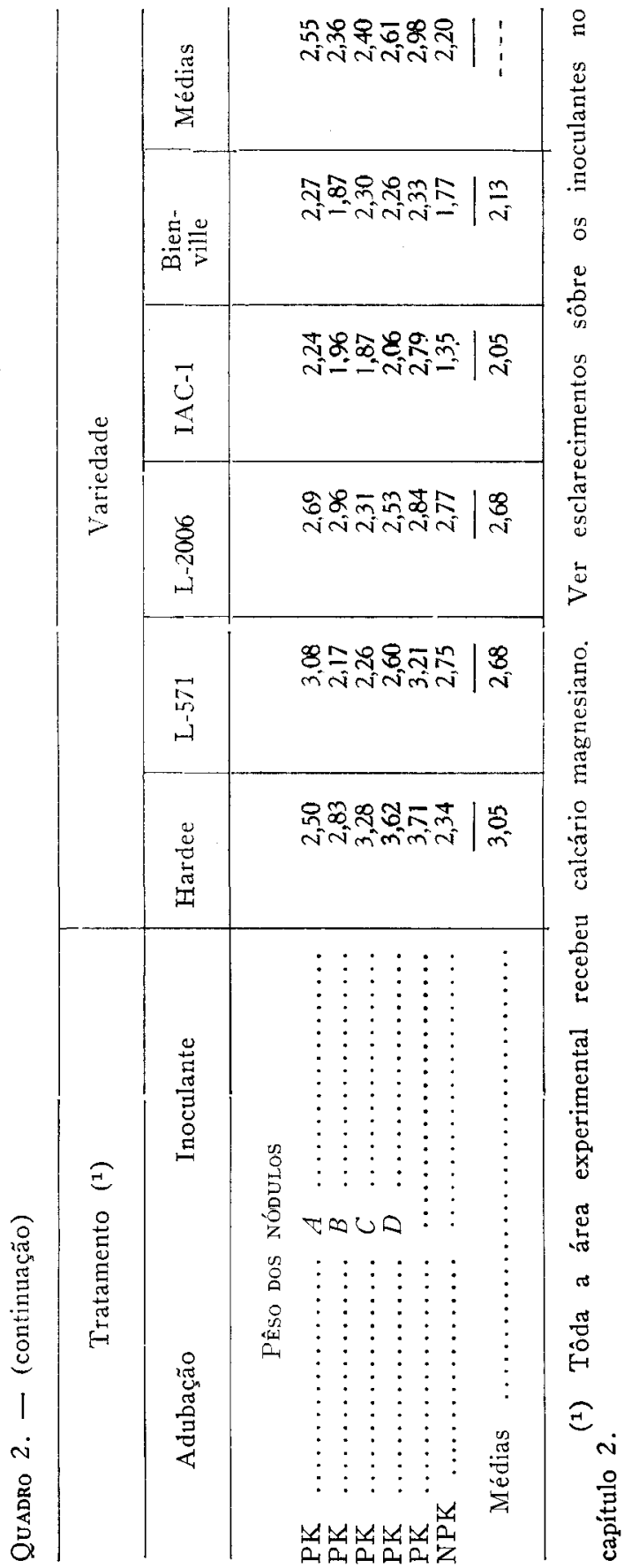


Os dados das produções obtidas figuram no quadro 3 . Na análise estatística dessas produções, o coeficiente de variação correspondeu a $28,6 \%$, nas parcelas, e a $15,2 \%$, nas subparcelas.

Houve diferenças altamente significativas entre as variedades. Segundo o teste de Tukey ao nível de $5 \%$ de probabilidade, a variedade Hardee foi estatisticamente equivalente à IAC-1 e superior às variedades L-2006, L-571 e Bienville. IAC-1 não diferiu de L-2006 e L-571, mas foi superior a Bienville. Dando-se valor 100 à produção média de Hardee, os indices referentes às variedades IAC-1, L-2006, L-571 e Bienville seriam, respectivamente, 88, 85, 78 e 76.

Não houve diferenças significativas entre os tratamentos (adubação e inoculantes), nem foi significativa a interação tratamentos $\mathrm{x}$ variedades. Deve-se registrar, porém, que em média das variedades e em relação ao tratamento $\mathrm{PK}$ a adubação nitrogenada deprimiu a produção, e as respostas aos inoculantes $A, B, C$ e $D$ corresponderam a, respectivamente, $-5,+8,-6$ e +3 por cento.

Embora a interação inoculantes $\mathrm{x}$ variedades não tenha sido significativa, convém examinar como as variedades reagiram aos inoculantes. Para Hardee, os mais eficientes foram $B$ e $D$, que proporcionaram aumentos de, respectivamente, $10 \%$ e 9\%; para L-571, também $B$ e $D$, com aumentos de $14 \%$ e $11 \%$; para L-2006, $B, C$ e $D$, com aumentos de 11,16 e 11 por cento; para IAC-1, somente $B$, com aumento de $8 \%$; para Bienville, nenhum, pois todos êles provocaram depressões. É interessante notar que, pràticamente, o inoculante $A$ não aumentou a produção de qualquer das variedades; $B$ só não aumentou a de Bienville; $C$, que aumentou a de L-2006, deprimiu as das demais variedades em 8 a 15 por cento; $D$, eficiente para Hardee, L-571 e L-2006, não aumentou a produção de IAC-1 e deprimiu a de Bienville em 19 por cento.

Óleo e proteina - Os teores de óleo e proteína encontrados nas sementes são apresentados no quadro 4.

Vê-se que, em média das variedades, os tratamentos com e sem inoculantes ou nitrogênio pouco modificaram os teores em estudo. Intre as variedades, porém, as diferenças foram bem maiores. Em média dos diversos tratamentos, as variedades mais ricas de óleo - Bienville e Hardee - superaram a mais pobre - I -571 - em 10 por cento. Quanto à proteína, a variedade mais rica foi justamente L-571, que 
H. A. A. Mascarenhas \& outros

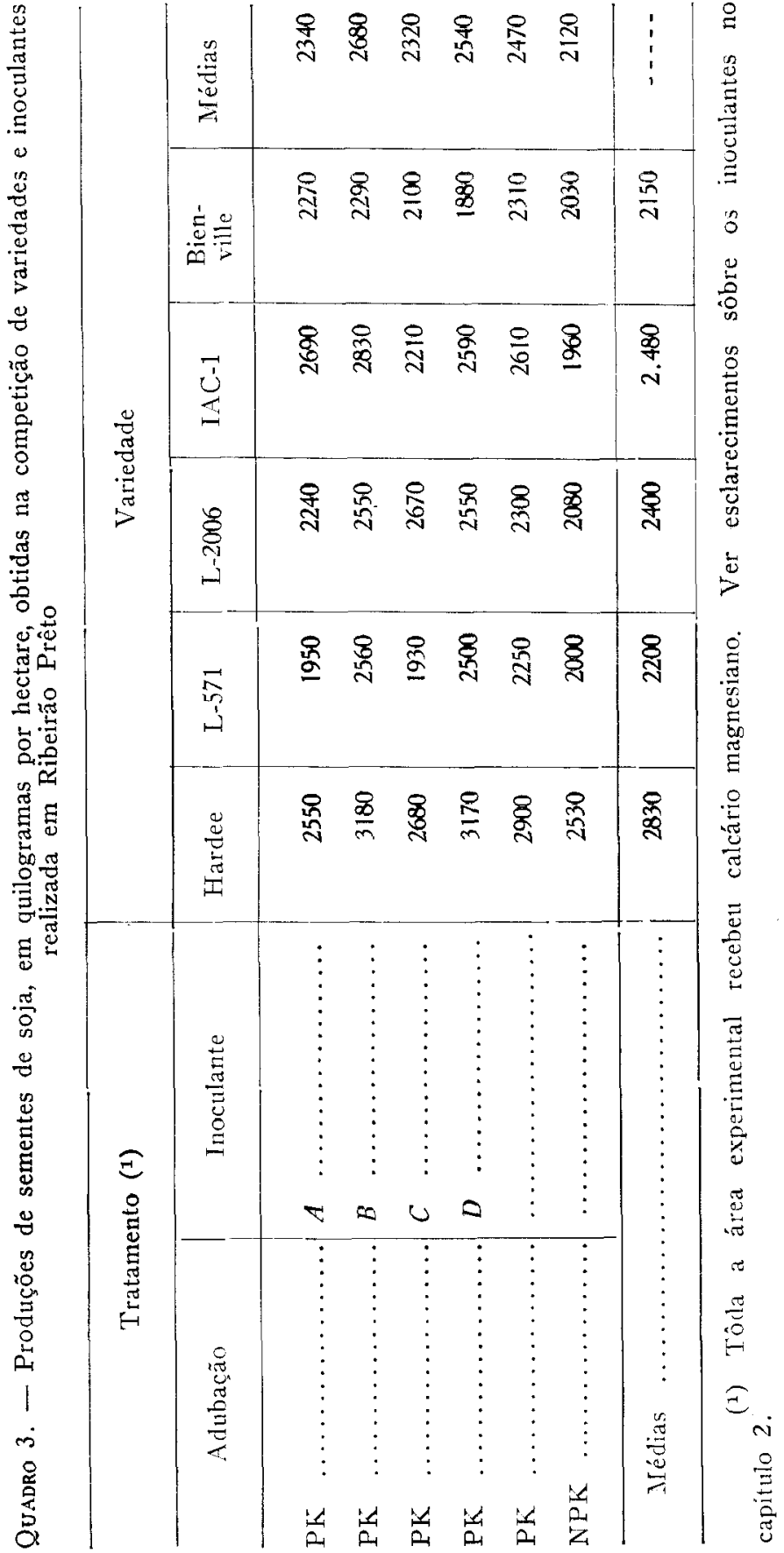




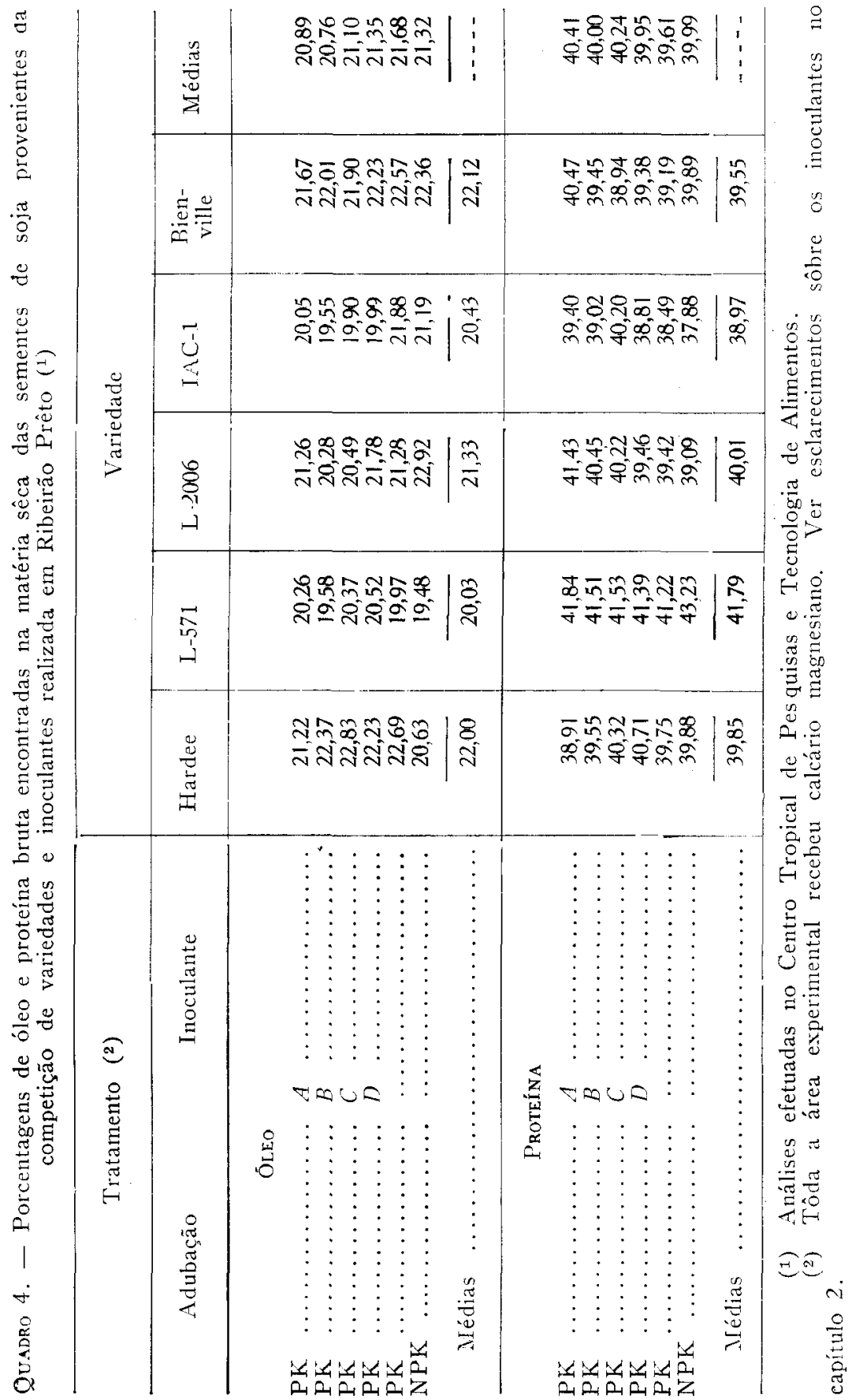


superou Hardee em 5 por cento, e a variedade mais pobre - IAC-1 em 7 por cento.

\section{4 - DISCUSSÃO}

O que se disse no capítulo anterior é suficiente para esclarecer a importância relativa das variedades.

A falta de reação significativa aos inoculantes estudados não quer dizer que êles sejam ineficientes, pois que, rias condiçôes da presente experiência, a adubação nitrogenada também não aumentou a produção de qualquer das variedades. Aliás, a análise foliar mostrou que o teor de nitrogênio nas plantas das parcelas adubadas com PK (sem inoculantes) foi estatisticamente equivalente aos encontrados nas adubadas com NPK, bem como nas que receberam, em adição a PK, os inoculantes $A, B$ e $D$, indicando que o solo utilizado estava bem provido de nitrogênio assimilável.

É verdade que os inoculantes não aumentaram a nodulação. Mas o fato é que, embora a experiência tenha sido instalada numa área que nunca teve cultura de soja, a nodulação, mesmo nos tratamentos que não tiveram inoculantes experimentais, foi muito intensa. Isso indica, por sua vez, que no solo já existiam bactérias capazes de provocar abundante nodulação. Se essas bactérias eram eficientes como fixadoras de nitrogênio nas variedades de soja estudadas, os dados disponíveis não permitem esclarecer.

Para ilustrar a complexidade do assunto, convém mencionar que cm outra experiência (1), conduzida simultâneamente na mesma gleba, com soja da variedade Pelicano, a nodulação foi tão farta, em todos os canteiros, que mascarou o efeito da proporcionada pela inoculação experimental. Todavia, nessa experiência, o inoculante usado aumentou consideràvelmente a produção de sementes, indicando que as bactérias preexistentes no solo eram ineficientes como fixadoras d!c nitrogênio, pelo menos na variedade Pelicano.

\section{5 - CONCLUSOES}

Da experichcia relatata, na qual se estudou, em solo latosol Roxo, o comportamento de cinco variedades de soja cujas sementes foram 
inoculadas, ou não, com quatro diferentes misturas de estirpes de Rhizobium, podem-se tirar as seguintes conclusões gerais:

a) Em média dos tratamentos: a produção de sementes da varielade Hardee foi estatisticamente equivalente à de IAC-1 e superior às de L-2006, I-571 e Bienville. A de IAC-1 também foi superior à de Bienville, mas equivalente às de L-2006 e L,-571. Dando-se valor 100 à produção de Hardee, os índices referentes às de IAC-1, L-2006, I_-571 e Bienville seriam, respectivamente, $88,85,78$ e 76 .

b) Em média das variedades, a adubação nitrogenada não aumentou a produção de sementes, e as pequenas respostas aos inoculantes não foram significativas. A julgar pelo efeito do nitrogênio, na produção e na análise foliar, o solo utilizado estava bem provido de nitrogênio assimilável, o que tornou a inoculação pràticamente supérflua.

c) Embora a área escolhida para a experiência nunca tivesse cultura de soja, a nodulação foi abundante em todos os canteiros. Talvez por isso não se tenha observado, em média das variedades, aumento de nodulação em conseqüência do emprêgo de qualquer dos inoculantes estudados.

d) Conquanto a interação inoculantes $\mathrm{x}$ variedades não tenha sido significativa, convém registrar que, na produção de sementes, as variedades de soja reagiram diferentemente aos inoculantes comparados.

\section{SUMMARY}

BEHAVIOR OF SOYBEAN VARIETIES INOCULATED WITH DIFFERENT MIXTURES OF RHIZOBIUM STRAINS IN LATOSOL SOILS OF THE STATE OF SAO PAULO

The performance of five soybean varieties whose seeds were inoculated with four different mixtures of Rhizobium strains was studied at Ribeirão Prêto, State of São Paulo. In the seed yields. Harclee was statistically equivalent to IAC-1 and superior to L-2006, L-571 and Bienville. Mineral nitrogen did not increase the seed yields and the small responses to the inoculants were not significant. Although the experimental field had never been cropped with soybeans, the nodule formation was very good in all of the plots, so that no increase due to the experimental inoculants was observed.

\section{LITERATURA CITADA}

1. MASCARENHAS, H. A. A.; MIYASAKA, S.; FREIRE, E. S.; (;UIDO DI SORDI \& HELI LOPES. Adubarção da soja. V - Efeitos da inoculação das 
scmentes com Rhizobium e da subseqüênte "peletização" com pasta de carbonato dc cálcio, na ausência e na presença da calagem e da adubação nitrogenada. Bragantia 26:[143]-154, 1967.

2. SERVIÇO NACIONAL DE PESQUISAS AGRONOMICAS, COMISSÃO DE SOLOS. Levantamento de reconhecimento dos solos do Estado de São Paulo. Rio de Janeiro, Ministério da Agricultura, 1960. 634p. (Boletim 12) 